\title{
Pengaruh Latihan Burpee dan Box Jump terhadap Daya Ledak Otot Tungkai dan Kecepatan Renang 50 Meter Gaya Bebas
}

Teguh Wicaksono ${ }^{a}$, Wahyu Setia Kucahyaning Putri ${ }^{\text {b* }}$

${ }^{a} S D$ Negeri Tapelan I Kecamatan Ngraho, Kabupaten Bojonegoro, Indonesia

bProgram Studi Pendidikan Jasmani Kesehatan dan Rekreasi, Universitas Nahdlatul Ulama Sunan Giri, Bojonegoro, Indonesia

Correspondence: teguh23wicaksono@gmail.com

Received: 31 May 2017 Accepted: 27 April 2020 Published: 29 April 2020

\begin{abstract}
The research is almed ti analyze (1) The influence of burpee workout on leg muscle explosive power and swmming speed (2) The influence of box jump workout on workout on leg muscle explosive power and swimming speed (3) The difference of burpee and box jump workout on leg muscle explosive power and swimming speed. This research is quasi experimental research with quantitative descriptive analysis. It is a population research where the number of population and samples are same. They are 24 athletes which contain of 8 athletes in experimental group I, 8 athletes in experimental group II and 8 athletes in control group. The data research is ordinal pairing. In collecting data of leg muscle explosive power, the researcher uses stopwatch, jump md and scale while in collecting data of swimming speed. The researcher uses stopwatch. The data analysis uses normality test, homogeneity test and T-test with SPSS 20.0. The finding of this research reveals that : (1) burpee workout can increase the leg muscle explosive power up to $6,98 \%$ and swimming speed up to $4,55 \%$ (2) box jumping workout can increase the leg muscle explosive power up to $8,13 \%$ and swimming speed up to $3,53 \%$ (3) box jump workout is the most effective workout to increase leg muscle explosive power and swimming speed in swimming club's athletes of Taman Tirta Bojonegoro.
\end{abstract}

Keywords: Burpee; Box Jump; Explosive Power.

\begin{abstract}
Abstrak
Penelitian ini bertujuan untuk menganalisis tentang: (1) pengaruh latihan burpee terhadap daya ledak otot tungkai dan kecepatan renang (2) pengaruh latihan box jump terhadap daya ledak otot tungkai kecepatan renang (3) perbedaan latihan burpee dan box jump terhadap daya ledak otot tungkai dan kecepatan renang. Penelitian ini merupakan penelitian eksperimen semu dengan pendekatan deskriptif kuantitatif. Penelitian ini merupakan penelitian populasi dimana jumlah populasi dan sampelnya sama yaitu 24 atlet yang terdiri dari 8 atlet kelompok eksperimen I, 8 atlet kelompok eksperimen II dan 8 atlet kelompok kontrol. Teknik pengambilan sampel menggunakan ordinal pairing. Proses pengambilan data daya ledak otot tungkai dengan menggunakan stopwatch, jump $M D$, timbangan sedangkan kecepatan renang stopwatch. Analisis data menggunakan uji normalitas, uji homogenitas dan uji beda dengan SPSS 20.0. Hasil penelitian menunjukkan bahwa: (1) latihan burpee dapat meningkatkan daya ledak otot tungkai sebesar $6,92 \%$ dan kecepatan renang sebesar 4,55\%, (2) latihan box jump meningkatkan daya ledak otot tungkai 8,13 \% dan kecepatan renang sebesar 3,53 \%, (3) latihan box jump merupakan latihan paling efektif untuk meningkatkan daya ledak otot tungkai dan kecepatan renang pada atlet klub renang Taman Tirta Bojonegoro.
\end{abstract}

Katakunci: Burpee; Box Jump; Daya Ledak. 


\section{Pendahuluan}

Olahraga merupakan aktivitas jasmani yang dilakukan dengan tujuan tertentu. Renang merupakan salah satu olahraga aktivitas air yang memiliki beberapa tujuan, antara lain sebagai prestasi, rekreasi atau pernyelamatan diri. Indikator prestasi renang meliputi kesesuaian teknik gaya renang dengan peraturan perlombaan renang serta kecepatan renangan. Menurut Kersting (2011) ada 3 faktor yang mempengaruhi catatan waktu seorang perenang antara lain waktu start (starting time), waktu gaya/berenang (stroking time) dan waktu pembalikan (turning time).

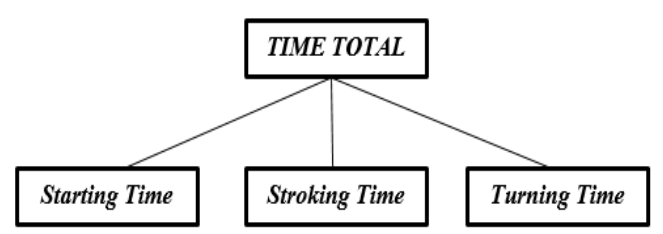

\section{Gambar 1. Indikator Prestasi Renang (Kersting, 2011)}

Peningkatan kemampuan dalam berbagai cabang olahraga harus memahami betul tentang prinsipprinsip. Menurut Hoffman (2014) ada beberapa prinsip-prinsip latihan yang perlu diperhatikan, yaitu : (1) Specificity principle, (2) Overload principle, (3) progression principle, (4) individuality principle, (5) principle of diminishing returns, (6) principle of reversibility.

Pemberian dosis latihan yang tepat juga dapat berpengaruh terhadap keberhasilan dalam peningkatan kemampuan seorang individu. Penentukan frekuensi, intensitas volume dan waktu istirahat dalam dosis latihan perlu dipertimbangkan. Menurut Lubis (2013) Intensitas latihan, pengulangan, order of exercise, frekuensi latihan, jumlah set, istirahat selama interval dan volume merupakan faktor penting dalam penentuan dosis latihan.

Plyometrics adalah latihan yang dirancang untuk menghasilkan kecepatan, kekuatan gerakan dan meningkatkan fungsi sistem saraf dengan tujuan untuk meningkatkan prestasi olahraga. Latihan plyometrics bertujuan meningkatkan kecepatan atau kekuatan otot kontraksi, sering dengan tujuan meningkatkan ketinggian melompat. Tujuan dari latihan plyometric untuk meningkatkan daya gerakan berikutnya dengan menggunakan kedua komponen alami, elastis otot, elastis tendon dan refleks peregangan (Shah, Salvi. 2012).

Menurut Mcleod (2010) latihan burpee dan box jump merupakan latihan dengan perkenaan otot utamanya pada otot-otot ekstremitas bawah yang digunakan saat start dan pembalikan dalam renang. Tekanan yang didapat oleh kaki dan lutut saat latihan ditujukan untuk melatih awalan (start) seorang perenang agar mendapatkan awalan (start) dan luncuran under water yang cepat dan ekplosif.

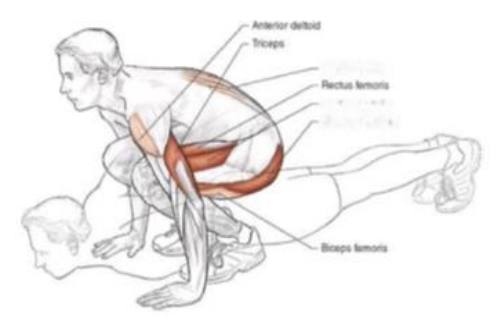

\section{Gambar 2. Bentuk Latihan Burpee (Mcleod, 2010)}

Otot-otot kaki membantu semua perenang meningkatkan kekuatan mereka selama perlombaan. Latihan ini merupakan latihan yang menghubungkan gerakan tangan dan kaki yang berguna untuk 
meningkatkan daya ledak perenang saat melakukan tolakan dari dinding (turning). Latihan burpee dengan perkenaan otot utama meliputi rectus femoris, vastus medialis, vastus intermedius, vastus lateralis, gluteus maximus, pectoralis major, triceps brachii. Atlet dapat mencapai lompatan tertinggi namun lompatan daya ledak membutuhkan sedikit waktu. Oleh karena itu untuk memperoleh kekuatan otot maksimum dari kelompok otot utama ekstremitas bawah membutuhkan latihan resistensi tertentu (Taheri, et. al. 2014)

Box jump adalah latihan untuk mengembangkan kecepatan dan kekuatan di ekstremitas bawah untuk meningkatkan kemampuan meledak dari Start blok dan menolak dinding saat pembalikan. Perkenaan otot saat latihan box jump utamanya meliputi rectus femoris, vastus medialis, vastus intermedius, vastus lateralis, gluteus maximus, gluteus medius, gastrocnemius, soleus.

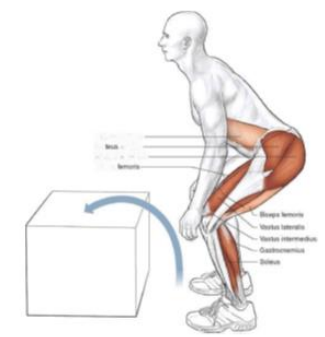

\section{Gambar 3. Bentuk Latihan Box Jump (Mcleod, 2010)}

Box jump untuk meningkatkan ketinggian melompat, yang dapat diartikan sebagai peningkatan jarak dan kecepatan take off di start blok. Start dan turn cukup penting dalam perlombaan renang karena atlet yang memiliki start dan turn baik maka akan semakin mempersingkat limit waktu renangnya. Hal ini juga akan berdampak baik untuk prestasi atlet renang itu sendiri.

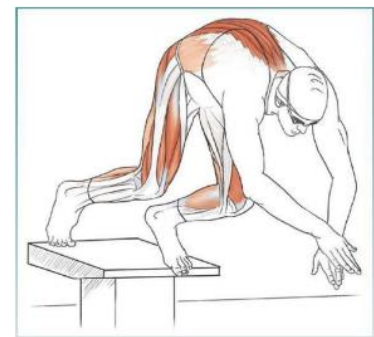

\section{Gambar 4 : Otot-otot yang Berperan saat Start (Mcleod, 2010)}

Indikator prestasi renang jarak pendek atau renang cepat 50 meter terletak pada kecepatan renang atau renang secepat-cepatnya. Dalam teknik start atau luncuran dibutuhkan daya ledak otot tungkai untuk mendapatkan luncuran atau tolakan dengan cepat dan jauh.(Anastain, 2012)

Penelitian terdahulu Milic et, al., (2008) menyatakan bahwa latihan plyometric box jump yang berkaitan dengan lompatan 2 kaki berkontribusi pada peningkatan ketinggian melompat rata-rata di satu kaki dan dua kaki. Perbedaan signifikan secara statistik tercatat antara kelompok eksperimen dan kelompok kontrol yang menyimpulkan bahwa model plyometric box jump dapat direkomendasikan untuk pelatihan lompatan. Hal ini telah dibuktikan secara eksperimental bahwa model latihan plyometric box jump enam minggu (dengan peningkatan intensitas latihan dari 70\% menjadi 100\%) mempengaruhi signifikan secara statistik peningkatan kekuatan ledakan otot kaki. Sedangkan Bensikaddour et, al., (2015) dalam penelitiannya menyimpulkan bahwa latihan plyometrics jump dapat mengembangkan kondisi fisik atlet. Penggunaan berat badan pada ketinggian tertentu dapat meningkatkan daya ledak pada otot-otot kaki. Menurut Miller et, al., (2006) menjelaskan bahwa latihan plyometrics berfungsi sebagai bentuk latihan yang cukup bervariasi mengingat banyak bentuk latihan plyometrics. Selama 6 minggu / masa latihan atlet mengalami peningkatan kondisi fisik meliputi kelincahan, kekuatan dan daya ledak. 


\section{Metode Penelitian}

Penelitian ini merupakan quasi eksperimen dengan menggunakan pendekatan deskriptif kuantitatif dengan desain penelitian pretest and posttest group design. Didalam penelitian ini ada beberapa prinsip yang perlu diperhatikan, yaitu adanya perlakukan, adanya kelompok kontrol, dan adanya ukuran keberhasilan, subyek yang ditempatkan tidak secara acak dari populasi tetapi diambil seluruh subjek dari kelompok yang telah terbentuk secara alami.

\begin{tabular}{|cccc|}
\hline $\mathrm{E}_{1}$ & $\mathrm{T1}_{1}$ & $\mathrm{X}_{1}$ & $\mathrm{~T}_{1}$ \\
$\mathrm{E}_{2}$ & $\mathrm{T1}_{2}$ & $\mathrm{X}_{2}$ & $\mathrm{~T}_{2}$ \\
$\mathrm{~K}$ & $\mathrm{~T}_{3}$ & - & $\mathrm{T}_{3}$ \\
\hline
\end{tabular}

Gambar 5. Pre-test and Post-test Group Design (Arikunto, 2014).

Variabel penelitian adalah segala sesuatu yang berbentuk apa saja yang ditetapkan oleh peneliti untuk dipelajari sehingga diperoleh informasi tentang hal tersebut, kemudian ditarik kesimpulan (Sugiyono, 2014). Dalam penelitian ini jumlah sampel yang digunakan sama dengan jumlah populasi. Populasi penelitian ini adalah atlet klub renang taman tirta bojonegoro yang berjumlah 24 dan dibagi menjadi 3 kelompok dengan teknik ordinal pairing tujuannya adalah untuk menyetarakan kualitas kemampuan orang coba dari masing-masing kelompok. Seluruh anggota akan dibagi menjadi 3 kelompok. Adapun langkah-langkahnya sebagai berikut:

a. Subyek diberikan tes awal pretest daya ledak otot tungkai dan kecepatan renang 50 meter gaya bebas.

b. Hasil tes daya ledak otot tungkai dan kecepatan renang 50 meter gaya bebas dicari z score

c. Setelah mendapatkan hasil z score maka dirangking dari terbesar sampai terkecil.

Tabel 1. Pembagian Kelompok Menggunakan Metode Ordinal Pairing

\begin{tabular}{ccc}
\hline $\begin{array}{c}\text { Kelompok } \\
\text { I }\end{array}$ & $\begin{array}{c}\text { Kelompok } \\
\text { II }\end{array}$ & $\begin{array}{c}\text { Kelompok } \\
\text { Kontrol }\end{array}$ \\
\hline 1 & 2 & 3 \\
6 & 5 & 4 \\
7 & 8 & 9 \\
12 & 11 & 10 \\
13 & 14 & 15 \\
18 & 17 & 16 \\
19 & 20 & 21 \\
24 & 23 & 22 \\
\hline
\end{tabular}

Keterangan :

Kelompok 1 : Kelompok Eksperimen 1 diberi latihan Burpee

Kelompok 2 : Kelompok Eksperimen 2 diberi latihan Box Jump

Kelompok 3 : Kelompok Kontrol sebagai pembanding dengan program latihan biasa

Pengumpulan data dalam penelitian ini diambil dari hasil pengukuran kecepatan renang 50 meter gaya bebas dengan stopwatch dan daya ledak otot tungkai dengan jump MD test. Dalam melakukan teknik pengumpulan data dapat dilakukan sebagai berikut:

1. Peneliti memberikan pre-test. Dalam pre-test terdiri dari tes kecepatan renang 50 meter gaya bebas dengan stopwatch dan daya ledak otot tungkai dengan jump MD test. Pre-test diberlakukan kepada kelompok eksperimen I, kelompok eksperimen II dan kelompok kontrol. 
2. Pemberian treatment selama 1,5 bulan (satu minggu terdiri dari $3 x$ pertemuan. Treatment diberikan kepada kelompok eksperimen I dan kelompok eksperimen II sedangkan kelompok kontrol tidak mendapat perlakukan (treatment).

Program latihan dibagi menjadi 3 kelompok, kelompok I latihan Burpee, kelompok II latihan box jump dan kelompok III yaitu kelompok kontrol latihan renang tanpa beban. Penyusunan program latihan merujuk pada buku Periodization Training for Sport (Bompa, 2015), Bishop dan Smith (2009), Lloyd, et.al. (2011), serta Dahab dan McCambridge (2009). Prosedur latihan (treatment) menurut Mcleod (2010) sebagai berikut :

1. Burpee

a. Posisi awal berdiri, turunkan tangan ke lantai selebar bahu (posisi jongkok).

b. Kedua kaki menendang ke belakang dan seperti posisi push up.

c. Menarik lagi kedua kaki kedepan dan kebali ke posisi jongkok dengan tangan masih menempel lantai selebar bahu.

d. Dilanjutkan melompat ke atas dengan posisi badan lurus dan begitu seterusnya.
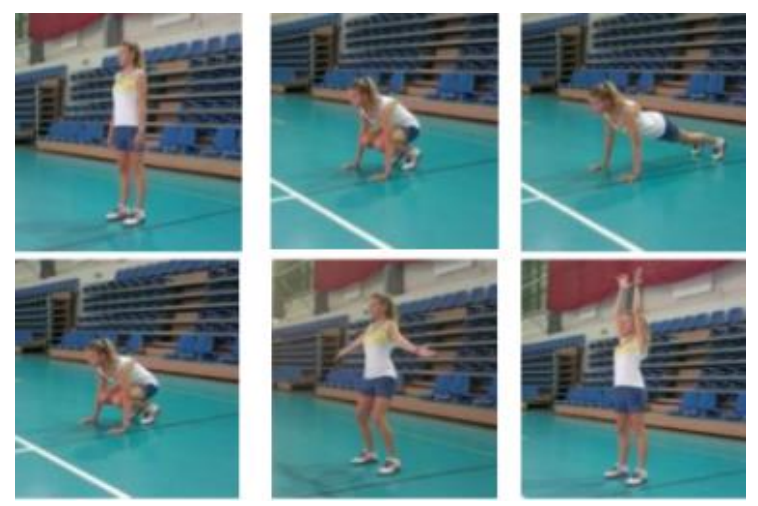

Gambar 6. Bentuk Latihan Burpee (Podstawki, et. al. 2014)

2. Box Jump

a. Berdiri 6 sampai 8 inci $(15-20 \mathrm{~cm})$ di belakang sebuah kotak dengan posisi setengah jongkok.

b. Melompat ke kotak dengan kedua kaki.

c. Dan langsung melompat ke bawah kotak dengan kedua kaki.

d. Dilanjutkan dengan kotak berikutnya dengan gerakan yang sama.

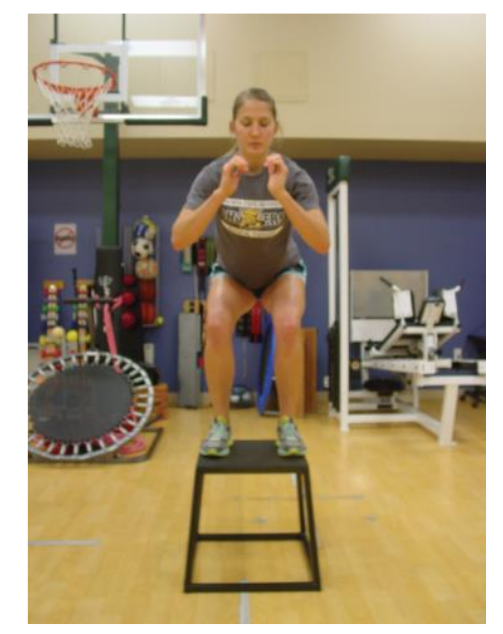

Gambar 7. Bentuk Latihan Box Jump (Davies, et. al, 2015) 
Pengumpulan data dilakukan untuk memperoleh informasi yang dibutuhkan dalam rangka mencapai tujuan penelitian (Kusumawati, 2014). Pengumpulan data kecepatan renang diukur menggunakan stopwatch, setiap atlet akan diberikan kesempatan berenang 50 meter dan diambil waktu terbaik. Pengukuran daya ledak otot tungkai menggunakan jump MD test dilakukan sebanyak dua kali dan diambil lompatan terbaik.

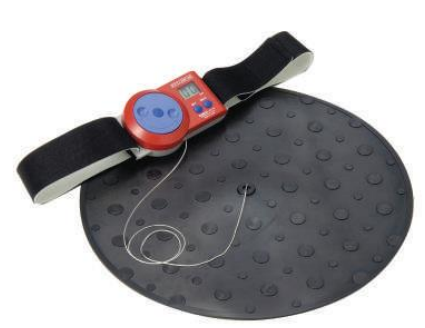

\section{Gambar 8. Alat Jump MD test}

Analisis data dilakukan pada variabel daya ledak otot tungkai dan kecepatan renang dengan cara memilih jenis analisis statistik yang sesuai. Deskriptif statistik berupa mean. Untuk menguji signifikansi nilai mean pretest dan posttest dalam kelompok digunakan paired samples t-test. Perbedaan mean antar kelompok dianalisis menggunakan One Way Anova yang dilanjut dengan Post Hoc Test dengan LSD.

\section{Hasil}

Hasil penelitian yang diperoleh berupa data variabel daya ledak otot tungkai dan kecepatan renang 50 $\mathrm{m}$ gaya bebas. Data hasil penelitian diolah dengan statistic deskriptif dan uji beda mean pretest dan posttest menggunakan paired samples t-test dapat dilihat pada tabel 2 sebagai berikut.

Tabel 2. Uji Beda Rerata Sampel Berpasangan

\begin{tabular}{lcccccc}
\hline \multirow{2}{*}{ Variabel } & \multicolumn{4}{c}{ Kelompok } & \multirow{2}{*}{ Sig. } & Ket. \\
\cline { 3 - 5 } & & KI & KII & KIII & & \\
\hline Kecepatan & Pre & 34,49 & 34,72 & 34,60 & 0,00 & Signifikan \\
renang & Post & 32,49 & 33,53 & 33,89 & 0,00 & Signifikan \\
& Pre & 437,06 & 435,63 & 414,60 & 0,00 & Signifikan \\
Daya ledak & Post & 467,35 & 471,08 & 430,48 & 0,00 & Signifikan \\
& & & & & & \\
\hline
\end{tabular}

Hasil pada tabel 2 menunjukkan perhitungan uji-t paired t-test pada kelompok I bahwa H0 ditolak dan Ha diterima karena nilai Sig. $0.000<$ nilai $\alpha=0,05$ dapat disimpulkan terdapat pengaruh yang signifikan dari pemberian latihan burpee terhadap daya ledak otot tungkai dan kecepatan renang 50M gaya bebas. Pada perhitungan uji-t paired t-test pada kelompok II bahwa H0 ditolak dan Ha diterima karena Sig. $0.000<$ nilai $\alpha=0,05$ dapat disimpulkan terdapat pengaruh yang signifikan dari pemberian latihan box jump terhadap daya ledak otot tungkai dan kecepatan renang 50M gaya bebas. Sedangkan Hasil dari perhitungan kelompok kontrol dengan melihat nilai Sig. (2-tailed) 0.001, bahwa H0 ditolak dan Ha diterima karena nilai Sig. $0.001<$ nilai $\alpha=0$,05. Sehingga dapat disimpulkan bahwa terdapat pengaruh latihan yang signifikan terhadap daya ledak otot tungkai dan kecepatan renang $50 \mathrm{M}$ gaya bebas. 
Tabel 3. Uji Beda Rerata Antar Kelompok

\begin{tabular}{cccc}
\hline \multicolumn{1}{c}{ Variabel } & F & Sig & Keterangan \\
\hline Daya Ledak Otot Tungkai & 47.670 & 0.000 & Signifikan \\
Kecepatan Renang & 54.962 & 0.000 & Signifikan \\
\hline
\end{tabular}

Berdasarkan tabel 3 di atas hasil perhitungan uji beda antar kelompok menggunakan One Way Anova dapat disimpulkan bahwa terdapat perbedaan yang signifikan nilai rerata daya ledak otot tungkai $(\mathrm{F}=$ 47.670, $\mathrm{p}<0.05)$ dan rerata kecepatan renang $(\mathrm{F}=54.962, \mathrm{p}<0.05)$. Untuk itu perlu dilakukan penghitungan lebih lanjut untuk mengetahui latihan yang lebih efektif dengan perhitungan post hoc test dan hasilnya adalah seperti dibawah ini:

Tabel 4. Hasil Perhitungan Post Hoc Test dengan LSD Daya Ledak Otot Tungkai

\begin{tabular}{llcc}
\hline Kelompok & & Mean difference & Signifikansi $(\mathrm{p})$ \\
\hline Burpee & box jump & -5.16 & .021 \\
& Kontrol & 14.40 & .000 \\
boxjump & Burpee & 5.16 & .021 \\
& Kontrol & 19.57 & .000 \\
kontrol & Burpee & -14.40 & .000 \\
& box jump & -19.57 & .000 \\
\hline
\end{tabular}

Menurut tabel di atas menunjukan bahwa adanya perbedaan yang signifikan antara ketiga kelompok. Perbedaan tersebut dapat dilihat dari Mean difference. Sehingga dari Mean difference tersebut memberian sebuah makna perbedaan pengaruh terhadap peningkatan daya ledak otot tungkai antar kelompok penelitian. Hal ini dapat diketahui dari nilai Mean difference, bahwa box jump lebih optimal memberikan peningkatan daya ledak otot tungkai dibandingkan dengan kelompok burpee maupun kontrol. Berikut tabel hasil Uji Post Hoc Test kecepatan renang 50M gaya bebas.

\section{Tabel 5. Hasil Perhitungan Post Hoc Test dengan LSD Kecepatan Renang 50M Gaya Bebas}

\begin{tabular}{llcc}
\hline \multicolumn{2}{c}{ Kelompok } & Mean difference & Signifikansi (p) \\
\hline Burpee & box jump & .316 & .000 \\
& kontrol & .796 & .000 \\
boxjump & burpee & -.316 & .000 \\
& kontrol & .480 & .000 \\
\multirow{3}{*}{ kontrol } & burpee & -.796 & .000 \\
& boxjump & -.480 & .000 \\
\hline
\end{tabular}

Menurut tabel diatas menunjukan bahwa adanya perbedaan yang signifikan antara ketiga kelompok. Perbedaan tersebut dapat dilihat dari Mean difference. Sehingga dari Mean difference tersebut memberian sebuah makna perbedaan pengaruh terhadap kecepatan renang 50M gaya bebas antar kelompok penelitian. Hal ini dapat diketahui dari nilai Mean difference, bahwa box jump lebih optimal memberikan peningkatan kecepatan renang 50M gaya bebas dibandingkan dengan kelompok burpee maupun kontrol. 


\section{Pembahasan}

Indikator prestasi renang jarak pendek atau renang 50 meter terletak pada kecepatan renang. Hal ini dikuatkan dengan penyataan Supriyanto dan Lismadiana, (2013) bahwa Atlet dikatakan memiliki prestasi renang yang baik apabila catatan waktunya lebih pendek dari waktu prestasinya.

Latihan sangat penting dalam meningkatkan prestasi atlet dalam setiap cabang olahraga. Berdasarkan hasil penelitian ini, kelompok eksperimen 1 (latihan burpee) mengalami peningkatan daya ledak otot tungkai sebesar $4.82 \%$ dan kecepatan renang sebesar $4.55 \%$. Menurut Mcleod (2010) latihan burpee merupakan latihan yang menghubungkan gerakan tangan dan kaki yang berguna untuk meningkatkan daya ledak otot perenang saat melakukan tolakan dari dinding (turning) dan tekanan yang didapat oleh kaki dan lutut ditujukan untuk melatih awalan (start) agar mendapatkan lompatan dan luncuran yang cepat dan eksplosif. Hal ini didukung juga penyataan Menurut Du dan Chen (2014) yang menyatakan bahwa dalam kondisi normal, perenang tidak harus mengurangi kecepatan ketika akan melakukan pembalikan dan harus menjaga momentum sehingga membantu menyelesaikan gerakan rotasi (salto), ketika melakukan pembalikan salto, kecepatan berputar bisa dipercepat dan melakukan push off atau dorongan kaki di dinding kolam, meletakan 2 lengan lurus ke depan, kepala tetap menghadap bawah yang berfungsi mengurangi tekanan air ketika mendapat dorongan dari kaki.

Kelompok eksperimen II (latihan box jump) mengalami peningkatan daya ledak otot tungkai sebesar $5.84 \%$ dan kecepatan renang sebesar $3.53 \%$. Hasil tersebut sejalan dengan hasil penelitian terdahulu dalam journal physical education and sport dari Milic, et.al (2008) menyimpulkan bahwa latihan plyometric box jump dengan lompatan 2 kaki berkontribusi pada peningkatan ketinggian lompatan rata-rata pada 1 kaki maupun 2 kaki sehingga latihan plyometric box jump direkomendasikan untuk peningkatan ledakan otot kaki. besaran peningkatan tersebut dapat dikatakan bahwa untuk meningkatkan daya ledak otot tungkai pemberian latihan box jump lebih efektif daripada latihan burpee, begitu juga dengan peningkatan kecepatan renang 50M gaya bebas, pemberian latihan boxjump lebih efektif daripada latihan burpee. Hal tersebut juga dikuatkan dengan penelitian terdahulu dari Bensikaddour, et.al (2015) dalam Swedish journal of scientific research yang menyatakan bahwa latihan plyometrics jump dapat mengembangkan kondisi fisik atlet dan penggunaan berat badan pada ketinggian tertentu dapat meningkatkan daya ledak pada otot-otot kaki.

\section{Simpulan dan Rekomendasi}

Berdasarkan hasil dan pembahasan diatas, maka dapat disimpulkan bahwa ada pengaruh yang signifikan latihan burpee dan box jump terhadap daya ledak otot tungkai dan kecepatan renang 50M gaya bebas namun ada perbedaan pengaruh antara keduanya yaitu latihan box jump lebih efektif untuk meningkatkan daya ledak otot tungkai dan kecepatan renang 50M gaya bebas daripada latihan burpee.

Berdasarkan simpulan yang telah diuraikan, maka dikemukakan beberapa rekomendasi kepada pelatih, pemerhati kepelatihan dan peneliti sebagai upaya tindak lanjut dari hasil penelitian ini agar dapat benarbenar bermanfaat. Berdasarkan hasil penelitian bahwa penerapan latihan burpee dan box jump memberikan pengaruh daya ledak otot tungkai dan kecepatan renang 50M gaya bebas. Perlu diadakan penelitian lebih lanjut terkait tentang latihan burpee dan box jump terhadap daya ledak otot tungkai dan kecepatan renang 50M gaya bebas sehingga akan memunculkan kajian eksperimen yang lebih luas mengenai topik tersebut. Bagi peneliti selanjutnya, penelitian ini dapat dijadikan sebagai bahan masukan maupun perbandingan, jika peneliti ingin mengangkat masalah yang sejenis dengan penelitian ini. 


\section{Daftar Pustaka:}

Arikunto, (2014). Prosedur Peneltian. Jakarta: Rineka Cipta.

Bensikaddour, Habib, et.al. (2015). "The Effects of Using Plyometrics Exercises to Improve Some Physical Abilities and Performance in The Triple Jump". Swedish Journal of Scientific Research. 2: 11.

Bishop, Daniel dan Smith, Mark. (2009). Effect of Plyometrics Training on Swimming Block Start Performance in Adolescents. The Journal of Strength and Conditioning Research. 23: 2137-2142.

Bompa. (2015). Periodization Training for Sport. US: Human Kinetics.

Dahab, Katherine dan McCambridge, Teri. (2009). "Strength Training in Children and Adolescents: Raising the Bar For Young Athletes". Journal of Sports Health. 1:223-226.

Davies, et. al. (2015). Current Concepts of Plyometrics Exercise. The International Journal of Sport Physical Therapy. 10: 760-786.

Du, Geng dan Chen, Yongbing. (2014). "Swimming Speed Influence Factor Contribution Research Based on Biomechanic and Fluid Mechanic Analysis". Journal of Chemical and Pharmacentical Research. 6: 45-51.

Hoffman, Jay. (2014). Physiological Aspects of Sport Training and Performance. USA: Human Kinetics.

Kersting, Uwe. (2011). Biomechanics of Swimming. Seoul: Minimodule.

Kusumawati. (2015). Penelitian Pendidikan Penjasorkes. Bandung: Alfabeta.

Lubis, Johansyah. (2013). “Latihan Kekuatan Untuk Atlet Muda”. Jurnal IPTEK Olahraga.

Lloyd, Rhodri, et.al. (2011). “The Natural Development and Trainability of Plyometric Ability During Childhood. Strength and Conditioning Journal. 33: 23-31.

Mcleod, Ian. (2010). Anatomy Swimming. USA: Human Kinetics.

Miller, et.al. (2006). "The Effects of a 6 Week Plyometrics Training Program on Agility”. Journal of Sports Science and Medicine. 5: 459-465.

Milic, et.al. (2008). The Effect of Plyometric Training on The Explosive Strength of Leg Muscles of Volleyball Players on Single Foot and Two-Foot Takeoff Jumps. Journal Physical Education and Sport. 6: 169-179.

Podstawski, Robert, et. al. (2014). The Level of Strength and Endurance-Strength Abilities of Female Early Education Teachers as Examined by The Medicine ball Forward Throw and the 3 min. Lase Journal of Sport Science. 5: 93-109.

Shah, Salvi. (2012). Plyometrics Exercise. Journal of Health Sciences and Research. 2: 115-126.

Sugiyono, (2014). Metode Penelitian Pendidikan Pendekatan Kuantitatif, kulitatif dan R $\mho D$. Bandung : Alfabeta.

Supriyanto, Agus dan Lismadiana. (2013). "Penggunaan Metode Hypnoterapi untuk Meningkatkan Konsentrasi Start dalam Renang”. Jurnal IPTEK Olabraga. 5:2.

Taheri, Eskandar. et. al. (2014). The Effect of 8 Weeks of Plyometrics and Resistence Training on Agility, Speed and Explosive Power in Soccer Players. European Journal of Experimental Biology. 4: 383-386. 